A N N A L E S Annales de Bretagne et des Pays de l'Ouest

Anjou. Maine. Poitou-Charente. Touraine

$122-4 \mid 2015$

Varia

\title{
Paul d'Estournelles de Constant
}

Jean-Baptiste Bruneau

\section{OpenEdition}

Journals

Édition électronique

URL : http://journals.openedition.org/abpo/3172

DOI : $10.4000 / a b p o .3172$

ISBN : 978-2-7535-4882-4

ISSN : 2108-6443

Éditeur

Presses universitaires de Rennes

Édition imprimée

Date de publication : 15 décembre 2015

Pagination : 158-159

ISBN : 978-2-7535-4880-0

ISSN : 0399-0826

Référence électronique

Jean-Baptiste Bruneau, " Paul d'Estournelles de Constant », Annales de Bretagne et des Pays de l'Ouest

[En ligne], 122-4 | 2015, mis en ligne le 15 décembre 2015, consulté le 23 septembre 2020. URL :

http://journals.openedition.org/abpo/3172 ; DOI : https://doi.org/10.4000/abpo.3172 
en outre comment s'est poursuivie l'intégration à la deuxième génération, dimension fondamentale que L. P. Moch n'aborde pas. On ne peut en tout cas que recommander la lecture de ce livre stimulant, qui fera réfléchir et les historiens des migrations et les historiens de la Bretagne.

Jean LE BIHAN

Tison, Stéphane (dir.), Paul d'Estournelles de Constant. Concilier les nations pour éviter la guerre (1878-1924), Rennes, PUR, coll. « Histoire », 2015, 276 p.

La haute figure de Paul d'Estournelles de Constant (1852-1924) témoigne de la très grande qualité intellectuelle autant qu'humaine du personnel politique de la III République. Entré dans la carrière diplomatique en 1876, il s'illustre en Tunisie où, jeune diplomate, il est un des acteurs de l'élaboration du protectorat et du règlement des capitulations, puis à Londres. Conseiller d'ambassade auprès de l'ambassadeur William Waddington, il participe à l'instauration du protectorat à Madagascar et au règlement de la crise du Siam. Malgré ces débuts prometteurs, il quitte la carrière pour l'arène politique sans pour autant renoncer à son intérêt pour les affaires étrangères. Député de la Sarthe de 1895 à 1904, il est élu au Sénat de 1904 jusqu'à sa mort en 1924 où il siège à la Commission des Affaires étrangères.

C'est au sein de cette prestigieuse commission qu'il se montre un partisan infatigable de la paix dans une démarche qui, si elle n'est pas dénuée d'idéalisme, s'inscrit avant tout dans une démarche pragmatique. Observateur lucide de l'émergence de nouvelles puissances mondiales à l'orée du $\mathrm{xx}^{\mathrm{e}}$ siècle, il est animé par la volonté de préserver la paix dans un monde dont les hiérarchies que l'on pensait éternelles sont en train d'être remises en cause. À l'impossible retour en arrière comme à la crispation sur une suprématie fragile, d'Estournelles s'efforce de penser un monde nouveau. Conscient des fragilités du monde occidental, malgré l'imposant édifice impérial construit dans la seconde moitié du XIX ${ }^{e}$ siècle, et convaincu de l'inévitable émergence des périphéries du "monde fini ", il n'a de cesse d'imaginer le monde d'après. Il y a dans ce patriote un pessimiste qui prend acte de la fin annoncée de la domination européenne sur le monde et qui tente de penser les modalités de la survie du vieux continent dans un contexte où il ne peut plus prétendre à l'hégémonie. Convaincu de la menace mortelle que représentait, pour cette survie, une nouvelle guerre, il participe largement à l'élaboration d'un droit international, par sa présence à la conférence de La Haye de 1899 où il contribue à sauver le principe de la cour d'arbitrage, dont il réussit à renforcer les pouvoirs lors de la conférence de 1907. Il se montre par ailleurs un analyste perspicace des premiers effets de la mondialisation économique; convaincu de l'aspect inévitable de ce mouvement, il cherche à penser les cadres, économiques et politiques, susceptibles d'offrir la meilleure protection à une Europe dont il sait, sous la puissance apparente, la fragilité.

Les nombreuses critiques, en raison de son incessant plaidoyer pour la paix, couronné par la remise du prix Nobel en 1909, qui ne voient en lui qu'un utopiste, ne sont pas sans préfigurer celles qui accueillent l'action politique de Briand dans les années 1920. À bien des égards, les deux hommes partagent un même pessimisme, nourri d'une lecture sans illusion de la situation internationale. L'affaiblissement de l'Europe, son essoufflement économique, la menace permanente de la guerre, sont des réalités difficilement contestables. Maintenir une hiérarchie mondiale autour du souvenir de la puissance relève d'une illusion dangereuse dont la poursuite est promesse de nouveaux conflits. Si d'Estournelles ne propose pas de solution à cette 
fin programmée, à tout le moins à ce déclassement, il offre au moins les possibilités d'en différer l'échéance.

C'est cette figure méconnue que la publication de l'ouvrage dirigé par Stéphane Tison invite à redécouvrir. Fruit d'un travail original initié par Hervé Bois avec ses élèves du lycée Paul d'Estournelles de Constant de La Flèche, l'ouvrage s'ouvre sur une remarquable présentation de la vie du sénateur de la Sarthe qui offre une introduction aussi claire que stimulante. Cette ouverture est complétée par les très intéressantes contributions réunies par Stéphane Tison qui permettent de saisir toute la richesse de la pensée de d'Estournelles. Alain Messaoudi montre ainsi que l'étude de son action comme diplomate en Tunisie révèle une méthode, que la contribution de François Pavé sur « le péril jaune " confirme, celle d'un conciliateur, plus pragmatique qu'idéologue. C'est à partir du constat de l'inévitable reclassement des puissances mondiales que s'élabore une pensée européenne marquée par le souci de proposer une alternative aux soubresauts inévitables des impérialismes européens, alternative dont la Première Guerre mondiale témoigne de l'urgence. Si le cataclysme de la Grande Guerre semble infirmer les espérances de d'Estournelles, il révèle aussi, surtout, la nécessité de faire entrer définitivement l'Europe et le monde dans l'ère la paix (Stéphane Tison, Jean-Michel Guieu), entrée auquel le progrès technique, notamment celui de l'aéronautique, offre des possibilités nouvelles (Patrick Facon). À ces développements clairs et précis est adjoint un remarquable recueil des textes du sénateur de la Sarthe qui offrent un complément précieux aux articles des différents contributeurs.

On peut certes regretter que certains aspects de la pensée de d'Estournelles de Constant ne soient évoqués que de manière marginale (la question de son rapport aux idées socialistes, ses réflexions sur la nature du régime républicain, ses compétences dans le domaine économique, son ultime engagement pour le vote des femmes), mais c'est sans doute l'intelligence de cet ouvrage, au-delà de sa remarquable cohérence d'ensemble, que de soulever autant de questions qu'il apporte de réponses.

Jean-Baptiste BRUNEAU

Gugelot, Frédéric, La messe est dite. Le prêtre et la littérature d'inspiration catholique en France au XXe siècle, Rennes, PUR, coll. «Interférences ", 2015, 192 p.

Auteur d'une thèse remarquable et remarquée sur La conversion des intellectuels au catholicisme en France, 1885-1935 (Paris, CNRS Éditions, 1998, réédition en 2010), Frédéric Gugelot s'est intéressé plus particulièrement depuis à la figure de l'écrivain catholique. Il a dirigé notamment, avec Alain Dierkens, Fabrice Preyat et Cécile Vanderpelen-Diagre, le précieux ouvrage collectif La Croix et la bannière. L'écrivain catholique en francophonie (XVII -XXIe siècles), paru en 2007 aux Éditions de l'université de Bruxelles. Il donne ici une utile synthèse sur un thème jusque-là plus traité par les littéraires que par les historiens. Or c'est précisément l'intérêt de ce livre que d'analyser la production littéraire d'inspiration catholique consacrée au prêtre à la lumière du contexte social, culturel et religieux dans lequel elle s'inscrit.

L'introduction rappelle que la littérature catholique, en tant que littérature adjectivée, apparaît après la Révolution. Elle naît en réaction à la sécularisation qui réduit la religion à une opinion, et elle participe donc de la vaste entreprise de restauration chrétienne qui anime le catholicisme intransigeant face à la société moderne. Mais elle se développe et se structure véritablement à la fin du XIXe siècle, comme un élé- 